\title{
Article \\ A Comparison of Structure Determination of Small Organic Molecules by 3D Electron Diffraction at Cryogenic and Room Temperature
}

\author{
Taimin Yang ${ }^{1}{ }^{\circledR}$, Steve Waitschat ${ }^{2}$, Andrew Kentaro Inge ${ }^{1}$, Norbert Stock ${ }^{2}$, Xiaodong Zou ${ }^{1, *}$ and Hongyi Xu ${ }^{1, * \mathbb{C}}$ \\ 1 Department of Materials and Environmental Chemistry, Stockholm University, 10691 Stockholm, Sweden; \\ taimin.yang@mmk.su.se (T.Y.); andrew.inge@mmk.su.se (A.K.I.) \\ 2 Institut für Anorganische Chemie, Christian-Albrechts-Universität zu Kiel, 24118 Kiel, Germany; \\ swaitschat@ac.uni-kiel.de (S.W.); stock@ac.uni-kiel.de (N.S.) \\ * Correspondence: xzou@mmk.su.se (X.Z.); hongyi.xu@mmk.su.se (H.X.)
}

check for updates

Citation: Yang, T.; Waitschat, S.; Inge, A.K.; Stock, N.; Zou, X.; Xu, H. A

Comparison of Structure

Determination of Small Organic

Molecules by 3D Electron Diffraction at Cryogenic and Room Temperature. Symmetry 2021, 13, 2131. https:// doi.org/10.3390/sym13112131

Academic Editors: Partha Pratim Das, Arturo Ponce-Pedraza, Enrico

Mugnaioli and Stavros Nicolopoulos

Received: 28 July 2021

Accepted: 3 November 2021

Published: 9 November 2021

Publisher's Note: MDPI stays neutral with regard to jurisdictional claims in published maps and institutional affiliations.

Copyright: (c) 2021 by the authors. Licensee MDPI, Basel, Switzerland. This article is an open access article distributed under the terms and conditions of the Creative Commons Attribution (CC BY) license (https:// creativecommons.org/licenses/by/ $4.0 /)$.

\begin{abstract}
D electron diffraction (3D ED), also known as micro-crystal electron diffraction (MicroED), is a rapid, accurate, and robust method for structure determination of submicron-sized crystals. 3D ED has mainly been applied in material science until 2013, when MicroED was developed for studying macromolecular crystals. MicroED was considered as a cryo-electron microscopy method, as MicroED data collection is usually carried out in cryogenic conditions. As a result, some researchers may consider that 3D ED/MicroED data collection on crystals of small organic molecules can only be performed in cryogenic conditions. In this work, we determined the structure for sucrose and azobenzene tetracarboxylic acid $\left(\mathrm{H}_{4} \mathrm{ABTC}\right)$. The structure of $\mathrm{H}_{4} \mathrm{ABTC}$ is the first crystal structure ever reported for this molecule. We compared data quality and structure accuracy among datasets collected under cryogenic conditions and room temperature. With the improvement in data quality by data merging, it is possible to reveal hydrogen atom positions in small organic molecule structures under both temperature conditions. The experimental results showed that, if the sample is stable in the vacuum environment of a transmission electron microscope (TEM), the data quality of datasets collected under room temperature is at least as good as data collected under cryogenic conditions according to various indicators (resolution, $I / \sigma(I), C C_{1 / 2}(\%), R_{1}, R_{\text {int }}$, ADRA).
\end{abstract}

Keywords: 3D ED; MicroED; electron crystallography; structure determination; cryogenic TEM; room temperature

\section{Introduction}

Electrons are ideal radiation sources for diffraction and imaging experiments on submicron-sized crystals because of their strong interaction with matter. However, the strong interaction brings severe radiation damage at the same time. It is difficult to obtain high-resolution transmission electron microscope (HRTEM) images from organic crystals because acquiring high signal-to-noise ratio (SNR) HRTEM images requires a higher electron dose [1]. Electron diffraction, on the other hand, requires a much lower electron dose to achieve atomic resolution and it is suitable for studying organic crystals. In 1976, Dorset and Hauptmann applied direct methods for ab initio phasing of electron diffraction data from organic crystals [2]. In the early 1990s, Dorset et al. demonstrated ab initio structure determination of a wide range of organic crystals using electron diffraction data [3,4]. In all cases, crystal structure models were obtained from one or only a few 2D zone-axis electron diffraction patterns. With the development of digitized detectors, the collection of 3D electron diffraction data from a single submicron-sized crystal for structure determination became possible. Kolb et al. and Zou et al. independently developed 3D electron diffraction methods, named automated electron diffraction tomography (ADT) $[5,6]$ and rotation electron diffraction (RED) [7,8], respectively. In 2010, Kolb et al. demonstrated that 
it is possible to analyze structures of organics using ADT [9]. Abrahams et al. determined structures of two organic pharmaceutical compounds by continuous rotation 3D electron diffraction using a hybrid pixel detector in 2016 [10]. This was the first time that such a hybrid pixel detector was used for collecting 3D ED data, which has the advantages of high sensitivity, low noise and, short readout time. Later, several articles [11-17] described the routine of rapid structure determination for small organic molecules using 3D ED. Palatinus et al. showed that it was possible to determine hydrogen positions in both organic (paracetamol) and inorganic crystals by employing dynamical refinements [18]. In 2019, they determined the molecular absolute configuration for a pharmaceutical compound [19]. Electron diffraction methods were also applied for structure determination of micron- and nano-sized protein crystals under cryogenic conditions by several groups [20-25]. 3D ED can also be performed in nanobeam mode [26,27] and combined with 4D STEM [27] to study small organic molecules and protein crystals. To alleviate radiation damage, researchers showed that the structure model can be improved by merging small-wedge 3D ED datasets collected from multiple crystals [28]. Furthermore, recent results showed that it is even possible to solve unknown protein structures (phased from a homologue less than $40 \%$ in sequence identity or having different conformation compared to the molecular replacement model) by MicroED [29,30], and visualize ligand binding interactions with electron diffraction datasets [31].

With the achievements mentioned above, 3D ED is becoming a standalone and reliable method for structure determination. However, some established protocols and methods were focused on data collection of macromolecules and organic molecules in cryogenic conditions, and were integrated into the existing cryo-EM sample preparation workflow. MicroED was introduced as a subset of cryo-EM methods, and many researchers may think 3D ED experiments can only be performed in cryogenic conditions. In this work, we demonstrated the structure determination of sucrose and $\mathrm{H}_{4} \mathrm{ABTC}$ using $3 \mathrm{D}$ ED datasets. Furthermore, we showed the influence of temperature on data quality. In addition, we investigated the effects of data merging on structure determination under both temperature conditions. The understanding of the effect of temperature and data merging will help researchers to decide which temperature condition they should use during $3 \mathrm{D}$ ED data collection.

\section{Materials and Methods}

We chose two low-symmetry crystals, sucrose and azobenzene tetracarboxylic acid $\left(\mathrm{H}_{4} \mathrm{ABTC}, 358.3 \mathrm{Da}\right)$, as testing samples for the temperature comparison because these structures are stable under high vacuum in both temperature conditions. The sucrose crystals were obtained from a sugar cube for coffee and tea. The $\mathrm{H}_{4} \mathrm{ABTC}$ molecules were synthesized according to the literature [32] and $\mathrm{H}_{4} \mathrm{ABTC}$ crystals were formed from the unreacted linker during synthesis of a Zr-based metal-organic framework (MOF) [33]. The samples were crushed into fine powders in a mortar and deposited onto a lacey carbon TEM grid without using any solvents. 3D ED data were collected on a JEOL JEM-2100 with a $\mathrm{LaB}_{6}$ filament at both room temperature and cryogenic temperature. Two grids were prepared for each sample. These grids were loaded on a Gatan 914 cryo-transfer holder and half of them were cooled down from $\sim 300 \mathrm{~K}$ to $\sim 100 \mathrm{~K}$ in the microscope column. Data were collected by continuously rotating the crystal while collecting selected area electron diffraction (SAED) patterns simultaneously with an electron-diffractiondedicated hybrid pixel detector (Timepix, Amsterdam Scientific Instrument, Amsterdam, The Netherlands) running in continuous exposure mode $[10,23]$. Data were processed and merged by XDS [34]. The structures could be solved by using both SHELXT [35] and SIR2014 [36]. Structure refinement was performed using SHELXL [37,38]. 


\section{Results and Discussion}

\subsection{Sucrose}

For room and cryogenic temperature data collection, the crystals were continuously rotated at a constant speed of $1.13^{\circ} / \mathrm{s}$. By using an exposure time of $0.3 \mathrm{~s} /$ frame, approximately 180 electron diffraction patterns were collected in each dataset, covering a total rotation angle of $60^{\circ}$ on average. The data collection time on each crystal was less than $1 \mathrm{~min}$, with an accumulated electron dose of less than $5 \mathrm{e}^{-} / \AA^{2}$ (dose rate: $0.08 \mathrm{e}^{-} / \AA^{2} / \mathrm{s}$ ). In order to achieve high data completeness and redundancy, a total of 17 datasets were processed and merged using XDS (refer to Table 1). The resolution of these electron diffraction data extended up to $0.8 \AA$. All 23 non-H atoms in the asymmetric unit were located directly by using SHELXT, as well as SIR2014 (Figure 1C). The atom assignment was corrected manually since it is difficult for the software to distinguish $\mathrm{C}$ and $\mathrm{O}$ atoms with diffraction data. We first refined the structure without any hydrogen atoms and restraints for fair comparison. During structure refinement, the atomic displacement parameter (ADP) of more than half of the atoms was negative for datasets collected at liquid nitrogen temperature, as shown in Table 1 (refinement for comparison). In order to obtain the hydrogen position and compare the structure with a reference model, we then applied restraints in refinements against both datasets to get chemically sensible structures.
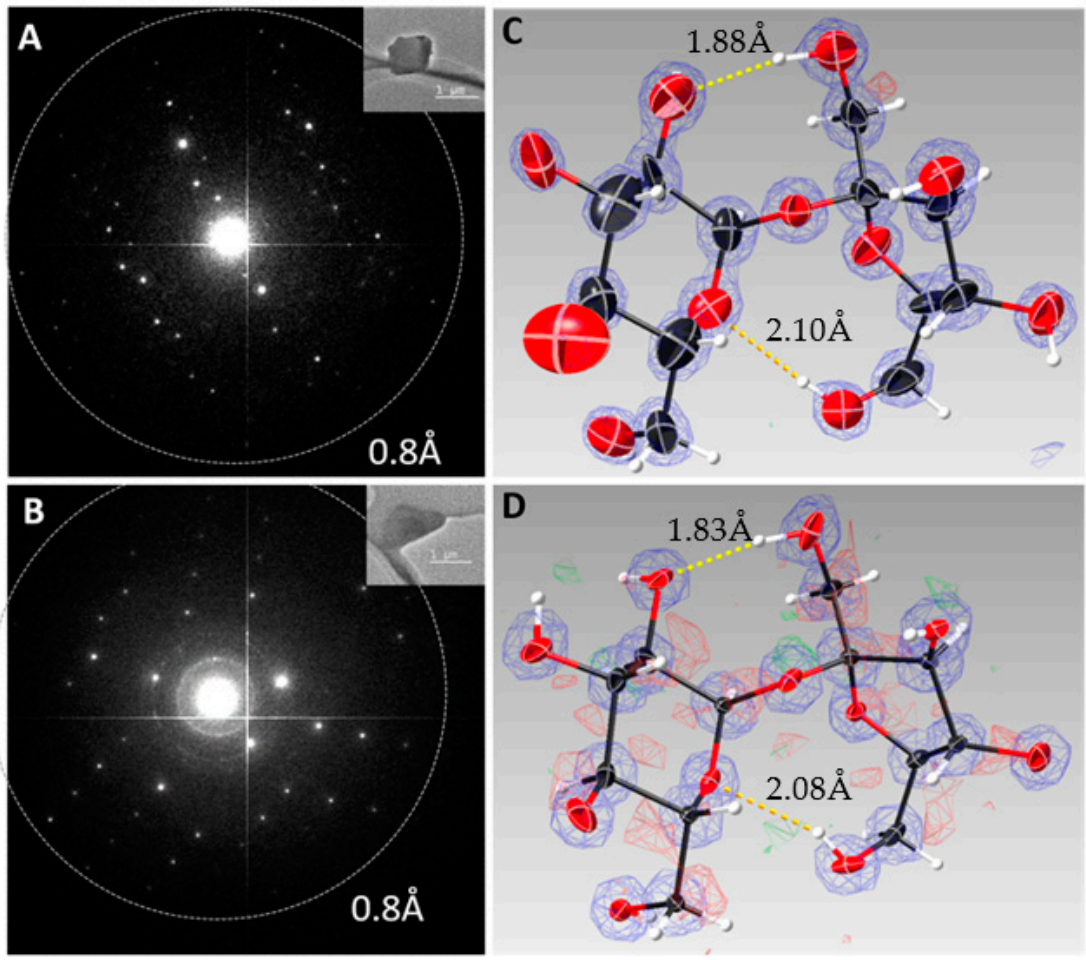

Figure 1. A typical electron diffraction pattern of sucrose crystal collected at (A) room temperature, (B) cryogenic condition. Note that the ice rings are visible in (B). The insets in $(\mathbf{A}, \mathbf{B})$ are typical crystals selected for data collection. Refined structure model of sucrose (asymmetric unit) against merged data collected at $(\mathbf{C})$ room temperature, $(\mathbf{D})$ cryogenic condition. The potential maps were obtained from SHELXL and visualized by SHELXLE. Blue volume means observed potential. Red volume means negative difference potential and green volume means positive difference potential. The threshold of observed and difference potential was set to $2 \sigma(0.65 \mathrm{~V})$ and $4 \sigma(0.2 \mathrm{~V})$, respectively. 
Table 1. Data and refinement statistics and structure parameters from merged sucrose datasets.

\begin{tabular}{|c|c|c|}
\hline & $\sim 300 \mathrm{~K}(0.80 \AA ̊)$ & $\sim 100 \mathrm{~K}(0.90 \AA ̊)$ \\
\hline \multicolumn{3}{|c|}{ Data Processing } \\
\hline Number of crystals & 17 & 12 \\
\hline Space group & $P 2_{1}$ & $P 2_{1}$ \\
\hline$a(\AA)$ & 11.19 [7] & $10.91[10]$ \\
\hline$b(\AA)$ & $9.06[7]$ & $8.78[9]$ \\
\hline$c(\AA)$ & 8.04 [12] & $7.85[9]$ \\
\hline$\beta\left(^{\circ}\right)$ & $103.6[10]$ & $103.4[8]$ \\
\hline Resolution $(\AA)$ & 0.8 & 0.9 \\
\hline$I / \sigma(I)$ & $3.61(1.32)$ & $3.31(2.24)$ \\
\hline$C C_{1 / 2}(\%)$ & $90.7 *(32.0 *)$ & $78.9 *(50.1 *)$ \\
\hline Redundancy & 16.60 & 16.32 \\
\hline$R_{\text {meas }}$ & $0.619(0.897)$ & $0.617(0.830)$ \\
\hline No. of reflections & 28601 & 18496 \\
\hline No. of unique reflections & 3203 & 2093 \\
\hline Completeness & $0.995(0.964)$ & $0.999(1)$ \\
\hline \multicolumn{3}{|c|}{ Refinement (for comparison) } \\
\hline No. of parameters & 93 (isotropic) & 93 (isotropic) \\
\hline No. of restraints & 1 & 1 \\
\hline$R_{1}\left(F_{\mathrm{o}}>4 \sigma\left(F_{\mathrm{o}}\right)\right)$ & 0.2024 & 0.2330 \\
\hline$R_{1}$ all & 0.2225 & 0.2401 \\
\hline GooF & 1.102 & 1.063 \\
\hline$w_{2}$ & 0.4974 & 0.4978 \\
\hline Number of negative ADPs & 0 & 14 \\
\hline
\end{tabular}

\begin{tabular}{ccc} 
& Refinement (for obtaining better structure) & \\
No. of parameters & 244 (anisotropic) & 243 (anisotropic) \\
No. of restraints & 5 & 4 \\
$R_{1}\left(F_{\mathrm{o}}>4 \sigma\left(F_{\mathrm{o}}\right)\right)$ & 0.1456 & 0.1974 \\
$R_{1}$ all & 0.1677 & 0.2058 \\
$R_{\mathrm{int}}$ & 0.5544 & 0.5205 \\
$\mathrm{GooF}$ & 1.021 & 0.945 \\
$\mathrm{w} \mathrm{R}_{2}$ & 0.3981 & 0.4085 \\
Hydrogen atoms found & 40 & 40 \\
Chemical formula & $\mathrm{C}_{24} \mathrm{H}_{40} \mathrm{O}_{22}$ & $\mathrm{C}_{24} \mathrm{H}_{40} \mathrm{O}_{22}$ \\
Weight (Da) & 680.56 & 680.56 \\
\hline Values in brackets are the data statistics of the highest resolution shell. The resolution cut was decided by the \\
statistical significance, which is denoted by an asterisk beside the $C_{1 / 2}$ value. The square brackets behind the \\
unit cell parameters stand for standard deviations. The unit cell parameters from the reference model were used \\
in the refinements against both datasets.
\end{tabular}

To better compare the structure refinements against datasets obtained at room temperature and cryogenic temperature, we performed structural analyses in two rounds. In the first round, we used the same SHELX input file as the starting point and refined the model against both datasets for comparison. In the second round, we further refined the structure in order to obtain the best structure models achievable from the two datasets.

In the first round, we refined the structure against both datasets isotropically using the same number of parameters (93) with one restraint. As shown in Table 1 , the final $R_{1}$ value is 0.2330 for data collected at cryogenic temperature and 0.2024 for data collected at room temperature. Furthermore, the structure obtained from the cryogenic temperature dataset contained 14 atoms with negative ADPs, while all the ADPs were positive in the structure obtained from the room temperature dataset.

In the second round, we further refined the structures against both datasets with anisotropic refinement and "XNPD" keyword to obtain the best structures. The "XNPD" keyword sets a lower bound for the eigenvalues of the $U_{\mathrm{ij}}$ tensor of all anisotropic atoms or the $U$ of an isotropic atom. For the room temperature dataset, a total of 244 parameters were refined using five restraints. Four of these restraints are distance restraints between carbon atoms and hydrogen atoms, and one of them is an ADP restraint. The final $R_{1}$ value 
is 0.1456 for 2147 strong reflections with $F_{\mathrm{o}}>4 \sigma\left(F_{\mathrm{o}}\right)$, and 0.1677 for all 3203 reflections. The atomic co-ordinates of the refined structure were compared with those of sucrose structures deposited in the CCDC database, which are obtained from neutron diffraction [39]. Since we are interested in investigating the feasibility of refining hydrogen atoms, the sucrose models were compared with this reference structure [40]. The average deviations from the reference model (ADRAs) are 0.05(2) $\AA$ for C and O atoms, and 0.17(9) $\AA$ for H atoms (Table 2 and supplementary material Table S1). The average bond lengths after refinement are 1.51(3) $\AA$ for C-C bonds, and 1.40(2) $\AA$ for C-O bonds (Table 3). The intermolecular and intramolecular hydrogen bond network could also be resolved by using the merged dataset collected at room temperature (Figures $1 \mathrm{C}$ and 2). These refinement results showed that, although the $R_{\text {int }}$ value is quite high, accurate structure was obtained after the refinement, possibly due to the increase in completeness and data redundancy. The significant increase in $R_{\text {int }}$ value has two contributing factors. The first being that the dynamical effects are ignored during data merging. Crystals of different size, shape, and orientation on the TEM grids contain different dynamical effects. However, current data-merging software developed for X-ray crystallography does not take this into account. The scaling of the intensities is far from optimal. The second factor is radiation damage. Even though the electron dose rate used in this study was very low $\left(0.08 \mathrm{e}^{-} / \AA^{2} / \mathrm{s}\right)$, we can only collect datasets with an average tilt range of $60^{\circ}$, since sucrose crystal is very beam sensitive. Even though data merging software has modelled radiation damage (e.g., DECAY in XSCALE), merging different datasets still accumulates errors and inconsistencies into the final merged HKL file, leading to a large $R_{\text {int }}$ value.

The statistics of the data collected at a cryogenic temperature can be found in Table 1. By comparing the data quality and difference Fourier map with data collected at room temperature, it is clear that the data quality is higher and difference Fourier map is cleaner for data collected at room temperature. Although the refinement statistics from $100 \mathrm{~K}$ data are comparable to those refined using data collected at room temperature, the atomic displacement parameters were constrained by using XNPD keyword. Otherwise, 14 atoms would have negative ADPs, as shown in Table 1. On the other hand, data collected at $100 \mathrm{~K}$, in general, have lower overall $I / \sigma(I)$ (3.31) compared with the overall $I / \sigma(I)$ from room temperature data (3.61) due to the ice contamination and inelastic scattering, as shown in Figure S1. The crystal mosaicity might increase during the cooling process and the reflection peaks would become less "sharp". The refined structured model has an average ADRA of 0.06(2) for $\mathrm{C}$ and $\mathrm{O}$ atoms (Table 2) and 0.20(11) for $\mathrm{H}$ atoms (Table S1). The average bond lengths are 1.54(2) $\AA$ for C-C bonds and 1.39(3) $\AA$ for C-O bonds (Table 3). The ADPs from the refinement with XNPD keyword showed that the ADP values for some atoms $(\mathrm{C} 1, \mathrm{C} 9)$ reached 0.01 , which is the minimum value imposed by XNPD keyword (Table S2). For experiments using a cryo-transfer holder and a microscope without a dedicated anticontamination device, it is rather difficult to avoid ice contaminations. The inelastic scattering events are increased due to microscopic ice crystals forming in the background. "Ice rings" are found in the diffraction pattern (Figure 1B). Their intensities increase towards the end of data collection because of accumulated contamination. In some cases, cryogenic conditions can even cause the deformations of crystals. In addition, we compared the difference Fourier maps in Figure 1C,D, and the map from merged room temperature datasets is much cleaner than other maps. Therefore, if the sample is stable under vacuum conditions and stable under electron beam, it is generally advisable to collect 3D ED data under ambient conditions. 
Table 2. Deviations of atomic positions between the reference structure of sucrose [39] and the structure determined from 3D ED datasets under both temperature conditions. The average deviations are 0.05(2) $\AA$ for $\mathrm{C}$ and $\mathrm{O}$ atoms for the merged dataset and 0.06(2) $\AA$ for the merged dataset collected at low temperature.

\begin{tabular}{|c|c|c|c|}
\hline Atom Label & ADRA (Å) & Atom Label & ADRA (Å) \\
\hline \multicolumn{2}{|c|}{$\sim 300 \mathrm{~K}$} & \multicolumn{2}{|c|}{$\sim 100 \mathrm{~K}$} \\
\hline $\mathrm{C} 1$ & 0.027 & $\mathrm{C} 1$ & 0.077 \\
\hline $\mathrm{C} 2$ & 0.076 & $\mathrm{C} 2$ & 0.046 \\
\hline $\mathrm{C} 3$ & 0.022 & C3 & 0.056 \\
\hline $\mathrm{C} 4$ & 0.029 & $\mathrm{C} 4$ & 0.064 \\
\hline C5 & 0.044 & C5 & 0.049 \\
\hline C6 & 0.046 & C6 & 0.038 \\
\hline $\mathrm{C} 7$ & 0.064 & $\mathrm{C} 7$ & 0.021 \\
\hline $\mathrm{C} 8$ & 0.071 & $\mathrm{C} 8$ & 0.073 \\
\hline C9 & 0.047 & C9 & 0.070 \\
\hline $\mathrm{C} 10$ & 0.060 & $\mathrm{C} 10$ & 0.059 \\
\hline $\mathrm{C} 11$ & 0.065 & $\mathrm{C} 11$ & 0.064 \\
\hline $\mathrm{C} 12$ & 0.063 & $\mathrm{C} 12$ & 0.082 \\
\hline $\mathrm{O} 1$ & 0.035 & $\mathrm{O} 1$ & 0.045 \\
\hline $\mathrm{O} 2$ & 0.041 & $\mathrm{O} 2$ & 0.078 \\
\hline $\mathrm{O} 3$ & 0.079 & $\mathrm{O} 3$ & 0.055 \\
\hline $\mathrm{O} 4$ & 0.057 & $\mathrm{O} 4$ & 0.058 \\
\hline O5 & 0.092 & O5 & 0.093 \\
\hline O6 & 0.033 & O6 & 0.039 \\
\hline O7 & 0.090 & O7 & 0.059 \\
\hline O8 & 0.059 & O8 & 0.070 \\
\hline O9 & 0.020 & O9 & 0.024 \\
\hline $\mathrm{O} 10$ & 0.031 & O10 & 0.046 \\
\hline O11 & 0.036 & O11 & 0.021 \\
\hline Average & $0.05(2)$ & Average & $0.06(2)$ \\
\hline
\end{tabular}

Table 3. Bond lengths found in the crystal structure of sucrose, which were refined from electron diffraction data.

\begin{tabular}{|c|c|c|c|c|c|}
\hline Atom1 & Atom2 & Bond Length (Å) & Atom1 & Atom2 & Bond Length (Å) \\
\hline \multicolumn{3}{|c|}{$\sim 300 \mathrm{~K}$} & \multicolumn{3}{|c|}{$\sim 100 \mathrm{~K}$} \\
\hline $\mathrm{C} 1$ & $\mathrm{C} 3$ & 1.533 & $\mathrm{C} 1$ & $\mathrm{C} 3$ & 1.581 \\
\hline $\mathrm{C} 2$ & $\mathrm{C} 4$ & 1.477 & $\mathrm{C} 2$ & $\mathrm{C} 4$ & 1.510 \\
\hline C3 & C5 & 1.515 & $\mathrm{C} 3$ & C5 & 1.535 \\
\hline $\mathrm{C} 4$ & C6 & 1.510 & $\mathrm{C} 4$ & C6 & 1.521 \\
\hline C5 & $\mathrm{C} 7$ & 1.552 & C5 & $\mathrm{C} 7$ & 1.559 \\
\hline C6 & $\mathrm{C} 8$ & 1.556 & C6 & $\mathrm{C} 8$ & 1.565 \\
\hline $\mathrm{C} 7$ & C9 & 1.488 & $\mathrm{C} 7$ & C9 & 1.563 \\
\hline $\mathrm{C} 8$ & C10 & 1.482 & $\mathrm{C} 8$ & C10 & 1.524 \\
\hline C9 & C11 & 1.517 & C9 & $\mathrm{C} 11$ & 1.537 \\
\hline $\mathrm{C} 10$ & C12 & 1.489 & $\mathrm{C} 10$ & $\mathrm{C} 12$ & 1.509 \\
\hline
\end{tabular}


Table 3. Cont.

\begin{tabular}{|c|c|c|c|c|c|}
\hline Atom1 & Atom2 & Bond Length $(\AA ̊)$ & Atom 1 & Atom2 & Bond Length $(\AA)$ \\
\hline \multicolumn{2}{|c|}{ C-C Average } & $1.51(3)$ & \multicolumn{2}{|c|}{ C-C Average } & $1.54(2)$ \\
\hline $\mathrm{C} 1$ & O1 & 1.427 & $\mathrm{C} 1$ & O1 & 1.402 \\
\hline $\mathrm{C} 1$ & O9 & 1.374 & $\mathrm{C} 1$ & O9 & 1.377 \\
\hline $\mathrm{C} 2$ & $\mathrm{O} 2$ & 1.432 & $\mathrm{C} 2$ & $\mathrm{O} 2$ & 1.497 \\
\hline $\mathrm{C} 3$ & $\mathrm{O} 3$ & 1.367 & $\mathrm{C} 3$ & $\mathrm{O} 3$ & 1.361 \\
\hline $\mathrm{C} 4$ & O1 & 1.410 & $\mathrm{C} 4$ & O1 & 1.403 \\
\hline $\mathrm{C} 4$ & $\mathrm{O} 4$ & 1.391 & $\mathrm{C} 4$ & $\mathrm{O} 4$ & 1.453 \\
\hline $\mathrm{C} 5$ & O5 & 1.375 & $\mathrm{C} 5$ & O5 & 1.385 \\
\hline C6 & O6 & 1.360 & C6 & O6 & 1.331 \\
\hline $\mathrm{C} 7$ & O7 & 1.416 & $\mathrm{C} 7$ & O7 & 1.633 \\
\hline $\mathrm{C} 8$ & O8 & 1.423 & $\mathrm{C} 8$ & O8 & 1.499 \\
\hline C9 & O9 & 1.399 & C9 & O9 & 1.485 \\
\hline $\mathrm{C} 10$ & $\mathrm{O} 4$ & 1.437 & $\mathrm{C} 10$ & $\mathrm{O} 4$ & 1.347 \\
\hline $\mathrm{C} 11$ & O10 & 1.411 & $\mathrm{C} 11$ & $\mathrm{O} 10$ & 1.433 \\
\hline $\mathrm{C} 12$ & O11 & 1.420 & $\mathrm{C} 12$ & O11 & 1.455 \\
\hline \multicolumn{2}{|c|}{ C-O Average } & $1.40(2)$ & \multicolumn{2}{|c|}{ C-O Average } & $1.39(3)$ \\
\hline
\end{tabular}

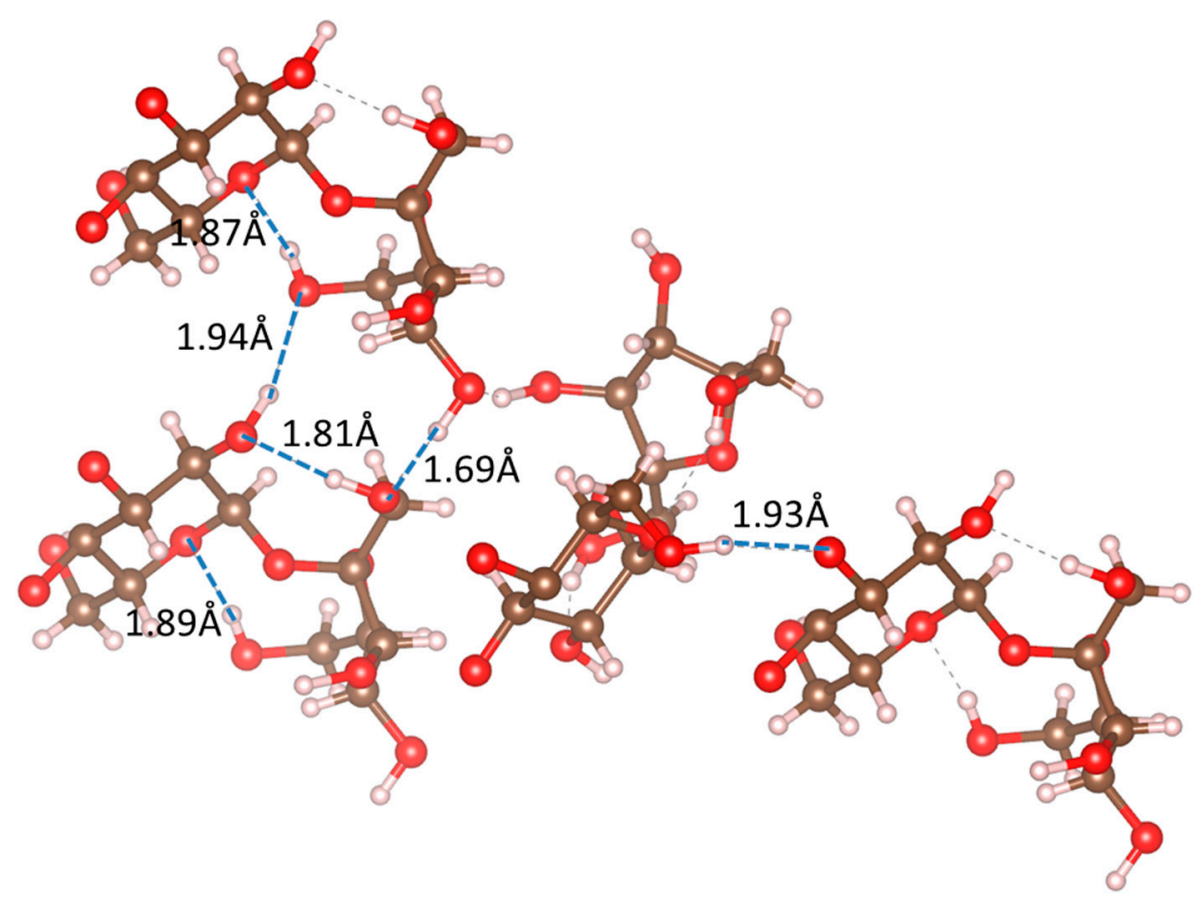

Figure 2. Details of the best sucrose structure obtained from merged room temperature data. The hydrogen bond network is highlighted.

\section{2. $\mathrm{H}_{4} A B T C$}

To further extend our observations, we use $\mathrm{H}_{4} \mathrm{ABTC}$ as another example. To our knowledge, no crystal structure of $\mathrm{H}_{4} \mathrm{ABTC}$ molecule has been reported previously. 3D ED datasets of $\mathrm{H}_{4} \mathrm{ABTC}$ crystals were collected at room temperature and under cryogenic conditions. The crystals were continuously rotated at a constant speed of $0.46^{\circ} / \mathrm{s}$. By using an exposure time of $0.5 \mathrm{~s} /$ frame, approximately $435-480$ frames are collected in each dataset, covering a total rotation angle of $100-110^{\circ}$ on average. The data collection time on each crystal is approximately $4 \mathrm{~min}$, with an accumulated electron dose of less than $20 \mathrm{e}^{-} / \AA^{2}$ (dose rate: $0.08 \mathrm{e}^{-} / \AA^{2} / \mathrm{s}$ ). For datasets collected at room temperature, the resolution of these electron diffraction data extended up to $0.80 \AA$. We merged multiple datasets to achieve higher completeness and data redundancy for structure determination. Direct methods were applied for the structure solution and all 78 non- $\mathrm{H}$ atoms in the 
asymmetric unit could be directly located using either SHELXT or SIR2014. The structure was refined using data up to $0.83 \AA$ resolution using SHELXL (Table 4). By examining the raw diffraction patterns (Figure $3 \mathrm{~A}, \mathrm{~B}$ ), we observed ice rings in all cryogenic temperature datasets. The $I / \sigma(I)$ and $C C_{1 / 2}$ in Table 4 indicates the data quality was reduced at high resolution in cryogenic datasets. $\mathrm{H}_{4} \mathrm{ABTC}$ crystallizes in the space group $P-1$, with three molecules in an asymmetric unit. The packing of these three molecules is shown in Figure 4A,B. Two molecules were parallel and had strong $\pi-\pi$ interactions between them, while the third one laid perpendicular to these two molecules. We adapted the evaluation strategy of sucrose crystals to $\mathrm{H}_{4} \mathrm{ABTC}$ crystals. We first used isotropic refinement with 314 parameters and no restraints for both merged datasets for the purpose of comparison. No hydrogen atoms were added and no negative ADPs were found during refinement. The final $R_{1}$ obtained for the room temperature dataset and cryogen dataset was 0.2596 and 0.2833 , respectively.

Table 4. Data and refinement statistics and structure parameters from merged $\mathrm{H}_{4} \mathrm{ABTC}$ datasets.

\begin{tabular}{|c|c|c|}
\hline & $\sim 300 \mathrm{~K}(0.8 \AA ̊)$ & $\sim 100 \mathrm{~K}(0.9 \AA)$ \\
\hline \multicolumn{3}{|c|}{ Data Processing } \\
\hline Number of crystals & 6 & 9 \\
\hline Space group & $P-1$ & P-1 \\
\hline$a(\AA)$ & $13.47[6]$ & $13.52[7]$ \\
\hline$b(\AA)$ & $14.63[12]$ & $14.63[17]$ \\
\hline$c(\AA)$ & $14.65[12]$ & $14.70[13]$ \\
\hline$\alpha\left({ }^{\circ}\right)$ & 98.55 & 99.40 \\
\hline$\beta\left(^{\circ}\right)$ & 105.90 & 106.06 \\
\hline$\gamma\left({ }^{\circ}\right)$ & 112.92 & 113.99 \\
\hline Resolution $(\AA)$ & 0.80 & 0.90 \\
\hline$I / \sigma(I)$ & $4.77(1.99)$ & $2.63(1.35)$ \\
\hline$C C_{1 / 2}(\%)$ & $97.1 *\left(88.4^{*}\right)$ & $90.8 *(73.0 *)$ \\
\hline Redundancy & 4.89 & 7.08 \\
\hline$R_{\text {meas }}$ & $0.209(0.595)$ & $0.395(0.648)$ \\
\hline No. of reflections & 48822 & 48984 \\
\hline No. of unique reflections & 8936 & 6770 \\
\hline Completeness & $0.897(0.814)$ & $0.935(0.752)$ \\
\hline \multicolumn{3}{|c|}{ Refinement (for comparison) } \\
\hline No. of parameters & 314 (isotropic) & 314 (isotropic) \\
\hline No. of restraints & 0 & 0 \\
\hline$R_{1}\left(F_{\mathrm{o}}>4 \sigma\left(F_{\mathrm{o}}\right)\right)$ & 0.2596 & 0.2833 \\
\hline$R_{1}$ all & 0.2878 & 0.3329 \\
\hline$R_{\text {int }}$ & 0.1843 & 0.3353 \\
\hline GooF & 1.115 & 1.055 \\
\hline$w_{2}$ & 0.6227 & 0.6858 \\
\hline \multicolumn{3}{|c|}{ Refinement (for obtaining better structure) } \\
\hline No. of parameters & 719 (anisotropic) & 703 (anisotropic) \\
\hline No. of restraints & 77 & 77 \\
\hline$R_{1}\left(F_{\mathrm{o}}>4 \sigma\left(F_{\mathrm{o}}\right)\right)$ & 0.1883 & 0.2029 \\
\hline$R_{1}$ all & 0.2146 & 0.2472 \\
\hline$R_{\text {int }}$ & 0.1843 & 0.3353 \\
\hline GooF & 1.142 & 1.085 \\
\hline $\mathrm{wR}_{2}$ & 0.4689 & 0.5273 \\
\hline Chemical formula & $\mathrm{C}_{96} \mathrm{H}_{52} \mathrm{~N}_{12} \mathrm{O}_{48}$ & $\mathrm{C}_{96} \mathrm{H}_{36} \mathrm{~N}_{12} \mathrm{O}_{48}$ \\
\hline Weight & 2141.51 & 2125.38 \\
\hline Hydrogen atoms found & 52 & 36 \\
\hline
\end{tabular}



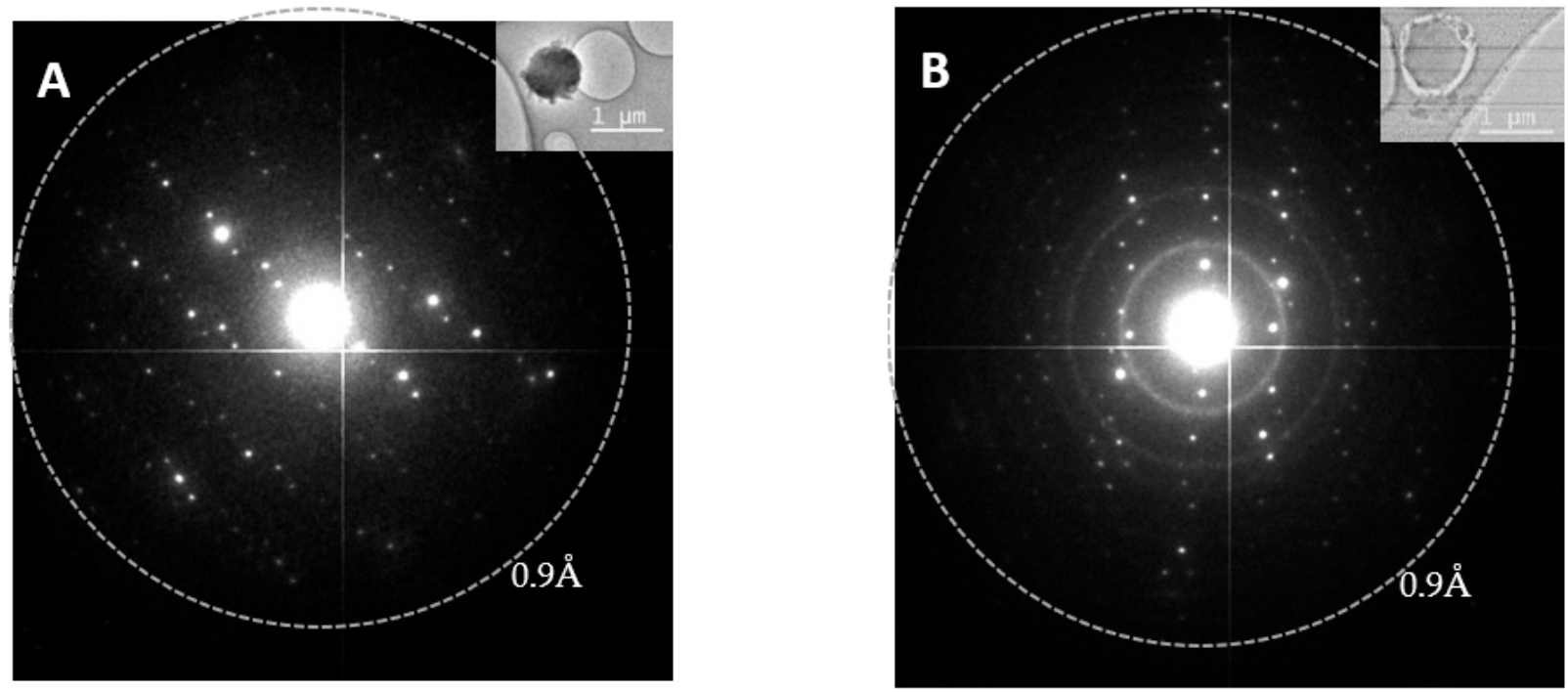

Figure 3. (A) Typical electron diffraction pattern of $\mathrm{H}_{4} \mathrm{ABTC}$ crystal collected at room temperature. (B) Typical electron diffraction pattern of $\mathrm{H}_{4}$ ABTC crystal collected under cryogenic conditions. The insets are images of typical microcrystals.
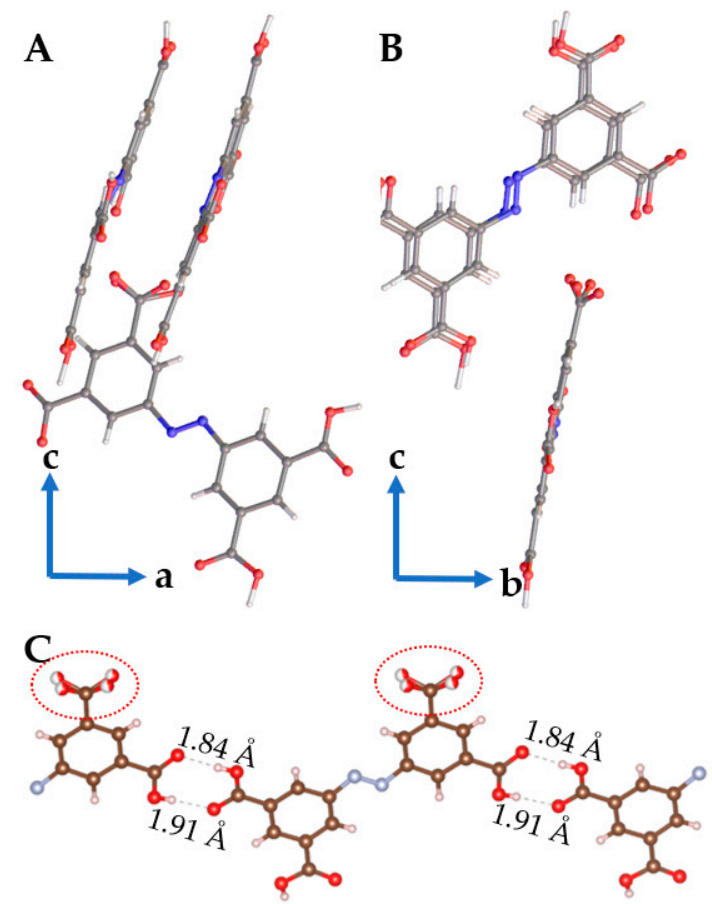

Figure 4. Detailed structure of the $\mathrm{H}_{4} \mathrm{ABTC}$ molecule refined from electron diffraction data collected under room temperature conditions, viewed along the (A) $b$-axis and (B) $a$-axis. (C) The terminal carboxyl groups are more flexible. The oxygen atoms in these groups are refined as disorders.

In order to obtain the best structures from both datasets, we further refined the ADPs anisotropically and only added the hydrogen atoms according to the difference Fourier map. "ISOR" restraints were used to avoid negative ADPs during refinement. The room temperature dataset was refined using 719 parameters with 77 restraints. The final $R_{1}$ value is 0.1883 for 6176 strong reflections with $F_{\mathrm{o}}>4 \sigma\left(F_{\mathrm{o}}\right)$ and 0.2146 for all 8143 reflections. The bond lengths are analyzed and shown in Table 5. The average bond lengths are 1.52(2) $\AA$ for single $\mathrm{C}-\mathrm{C}$ bonds, $1.43(2) \AA$ for $\mathrm{C}-\mathrm{C}$ bonds in a benzene ring, $1.30(4) \AA$ for $\mathrm{C}-\mathrm{O}$ bonds, 1.27(4) $\AA$ for $\mathrm{C}=\mathrm{O}$ bonds, $1.45(2) \AA$ for $\mathrm{C}-\mathrm{N}$ bonds, and 1.27(1) $\AA$ for $\mathrm{N}=\mathrm{N}$ bonds. It is possible to distinguish some hydroxyl groups and carbonyl groups by analyzing the bond lengths between $\mathrm{C}$ and $\mathrm{O}$ in the refined model. Furthermore, we could refine the 
disorder of the oxygen atoms in the terminal carboxyl groups with electron diffraction data (Figure 4C). Out of the 60 hydrogen atoms, 52 hydrogen positions, especially those associated with benzene rings, can be located from q-peaks, as well as from the difference Fourier map.

Table 5. Mean and standard deviation (in brackets) of bond length of $\mathrm{H}_{4} \mathrm{ABTC}$ structure solved from 3D ED datasets collected at room temperature and cryogenic temperature.

\begin{tabular}{|c|c|c|}
\hline Bond Type & Bond Length $(\AA)(\sim 300 \mathrm{~K})$ & Bond Length $(\AA)(\sim 100 \mathrm{~K})$ \\
\hline $\mathrm{C}-\mathrm{C}$ single bond & $1.52(2)$ & $1.53(2)$ \\
\hline $\mathrm{C}-\mathrm{C}$ benzene & $1.43(2)$ & $1.43(3)$ \\
\hline C-O carboxyl & $1.30(4)$ & $1.34(7)$ \\
\hline $\mathrm{C}=\mathrm{O}$ carboxyl & $1.27(4)$ & $1.29(6)$ \\
\hline $\mathrm{C}-\mathrm{N}$ single bond & $1.45(2)$ & $1.46(3)$ \\
\hline $\mathrm{N}=\mathrm{N}$ double bond & $1.27(1)$ & $1.26(4)$ \\
\hline
\end{tabular}

Similar to the sucrose case, datasets collected at $100 \mathrm{~K}$ produced worse refinement statistics (Table 4). The resolution is lower $(0.8 \AA$ to $0.9 \AA)$ and the overall $I / \sigma(I)$ is much lower (4.77 to 2.63) due to the higher background estimation by XDS (Figure S2). Subsequently, the refinement results are worse than the results from room temperature datasets. The final $R_{1}$ reached 0.2029 for strong reflections and 0.2472 for all reflections. The structure was refined with 703 parameters together with 77 restraints. We applied the same "ISOR" restraints as the room temperature dataset. We compared the anisotropic ADPs from both datasets and we found that the ADPs obtained from room temperature datasets are less elongated compared with ADPs from cryogenic temperature datasets, as shown in Figure 5. We think preferred orientation contributed to the elongation of the ADP ellipsoids. When a plate-like crystal is tilted to a high angle, the thickness of the sample increases, while the number of unit cells perpendicular to the electron beam decreases, causing the intensities of the reflections to decrease. The 3D ED data become anisotropic for plate-like crystals. This could become even more severe for cryogenic temperature measurement because of increased background. Next, we calculated the average bond lengths and the standard deviation for different types of bonds. Although the average bond length is almost the same as the bond length from the room temperature dataset, the standard deviation is greater, as shown in Table 5. In total, 36 hydrogen atoms could be located in the difference Fourier maps from the cryogenic temperature dataset. We note that the difference in the number of refined parameters (room temperature vs. cryogenic) is due to the fact that fewer hydrogen atoms were found from the cryogenic temperature dataset. Moreover, in both structure refinement studies of $\mathrm{H}_{4} \mathrm{ABTC}$, all the hydrogen atoms located on carboxyl groups were lost. The location of hydrogen atoms can be classified into three groups: (a) located on the benzene ring, (b) located between two carboxyl groups with hydrogen bonding interaction, and (c) carboxyl groups with no interactions. From our experience, the hydrogen atoms located on the benzene ring are the easiest to find. Hydrogen atoms in group (c) are the most difficult to locate because of the rotation of carboxyl groups, which also leads to the observed disorder in Figure 4C. We also noticed that the disordered oxygen atoms in the terminal carboxyl group became distorted for datasets collected under cryogenic conditions, while, for the room temperature data, the geometry of the disordered carboxyl group is consistent with prior chemical knowledge. These results indicate that the data quality and structural details obtained from datasets collected at room temperature are comparable with those obtained from cryogenic temperature datasets. 


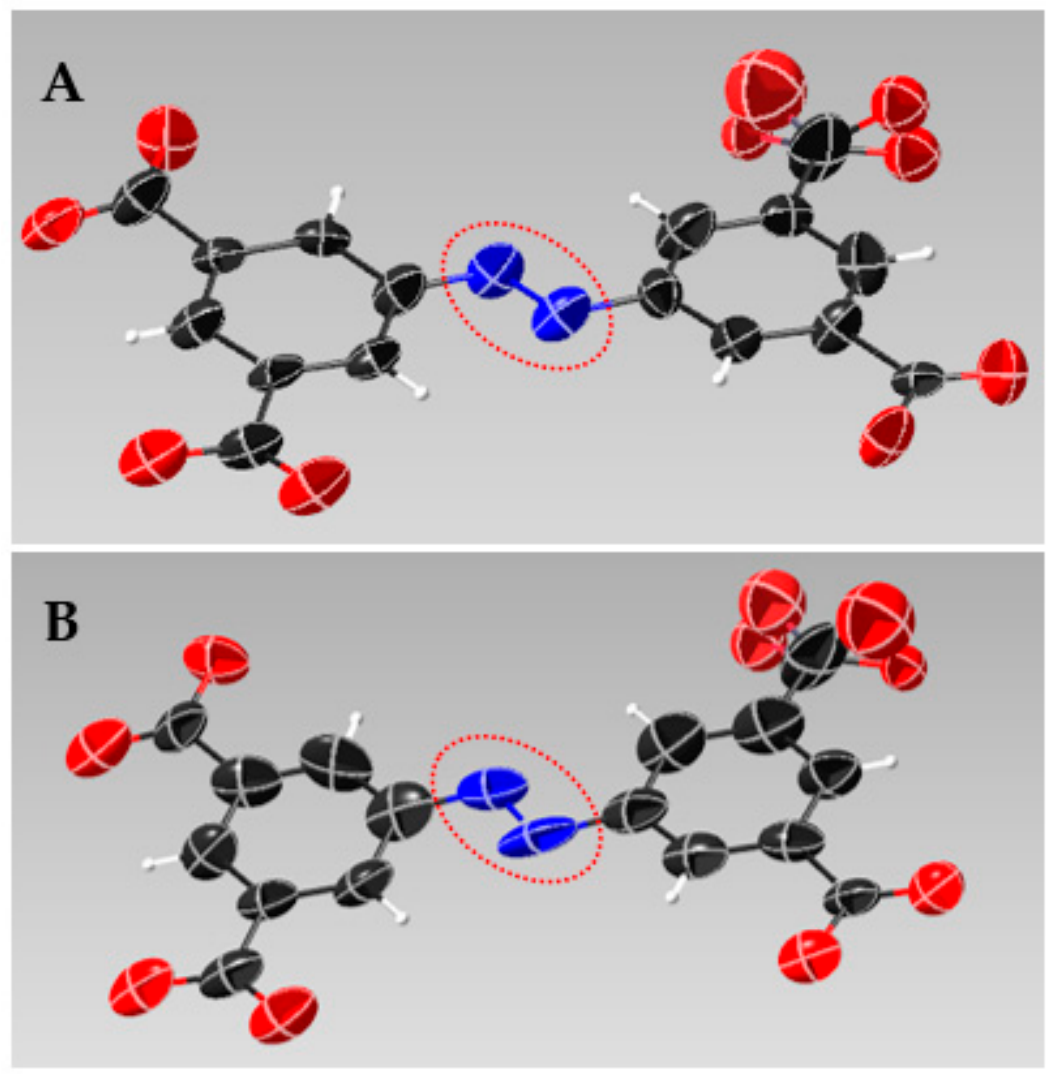

Figure 5. Structure comparison of one $\mathrm{H}_{4} \mathrm{ABTC}$ molecule from refinement for obtaining the best structures at (A) room temperature and at (B) cryogenic temperature.

\section{Conclusions}

In this work, we determined the structure of two small organic molecules by 3D ED in different temperature conditions. Among these two molecules, the structure of $\mathrm{H}_{4} \mathrm{ABTC}$ is unknown and it is the first crystal structure ever reported for this molecule. Based on the comparisons made between 3D ED datasets of sucrose and $\mathrm{H}_{4} \mathrm{ABTC}$ collected at room temperature and cryogenic conditions, we conclude that, if crystals are stable under vacuum and electron beam, comparable or better data quality and structure accuracy can be achieved by collecting data at room temperature. The fine details, such as hydrogen positions, disorders, and ADPs, are better revealed from merged room temperature datasets. However, under cryogenic conditions, the resolution and $I / \sigma(I)$ ratio could be lower if a dedicated cryo-electron microscope is not available. If the crystal is stable under vacuum conditions in TEM and electron beam, it is better to collect 3D ED data at room temperature, which is also simpler and more accessible. Otherwise, cryo-transfer and cooling techniques can be utilized. 3D ED is a capable method for structure determination of small organic molecules from nano- and micron-sized crystals, whether measured at liquid nitrogen temperature or at room temperature.

Supplementary Materials: The following are available online at https:/ / www.mdpi.com/article/ 10.3390/sym13112131/s1, Figure S1: Estimated background by XDS of sucrose data collected at (A) room temperature and (B) cryogenic temperature, Figure S2: Estimated background by XDS of $\mathrm{H}_{4}$ ABTC data collected at (A) room temperature and (B) cryogenic temperature, Table S1: ADRA of hydrogen atoms between the reference structure of sucrose [1] and structures determined from datasets obtained in both temperature conditions (2nd round of refinements for obtaining the best possible structure models), Table S2: Comparison between the ADPs of sucrose determined from merged datasets (refinement for obtaining better structure). ADPs close to 0.01 (the minimum ADP value set by "XNPD") are marked in red. 
Author Contributions: Conceptualization, T.Y., X.Z. and H.X.; methodology, all authors; validation, T.Y., X.Z. and H.X.; formal analysis, T.Y. and H.X.; resources, N.S., X.Z. and H.X.; data curation, H.X.; writing-original draft preparation, T.Y. and H.X.; writing-review and editing, T.Y., X.Z., H.X., N.S., A.K.I. and S.W.; visualization, T.Y. and H.X.; supervision, N.S., X.Z. and H.X.; funding acquisition, X.Z. and H.X. All authors have read and agreed to the published version of the manuscript.

Funding: The project is supported by the Swedish Research Council (2017-05333, H.X.; 2019-00815, X.Z.), the Knut and Alice Wallenberg Foundation (2018.0237, X.Z.), and the Science for Life Laboratory through the technique development grant (MicroED@SciLifeLab).

Institutional Review Board Statement: Not applicable.

Informed Consent Statement: Not applicable.

Data Availability Statement: The CIF files of the structures are deposited to the Cambridge Structure Database (CSD) with deposition codes: 2112205, 2112206, 2112207, 2112208, 2112209, 2112210, $2112211,2112212$.

Conflicts of Interest: The authors declare no conflict of interest.

\section{References}

1. Clabbers, M.T.B.; Abrahams, J.P. Electron diffraction and three-dimensional crystallography for structural biology. Crystallogr. Rev. 2018, 24, 176-204. [CrossRef]

2. Dorset, D.L.; Hauptman, H.A. Direct phase determination for quasi-kinematical electron diffraction intensity data from organic microcrystals. Ultramicroscopy 1976, 1, 195-201. [CrossRef]

3. Dorset, D.L. Structural Electron Crystallography; Springer: Boston, MA, USA, 1995; ISBN 978-0-306-45049-5.

4. Dong, W.; Baird, T.; Fryer, J.R.; Gilmore, C.J.; MacNicol, D.D.; Bricogne, G.; Smith, D.J.; O'Keefe, M.A.; Hovmöller, S. Electron microscopy at $1-\AA ̊$ resolution by entropy maximization and likelihood ranking. Nature 1992, 355, 605-609. [CrossRef]

5. Kolb, U.; Gorelik, T.; Kübel, C.; Otten, M.; Hubert, D. Towards automated diffraction tomography: Part I-Data acquisition. Ultramicroscopy 2007, 107, 507-513. [CrossRef] [PubMed]

6. Kolb, U.; Gorelik, T.; Otten, M. Towards automated diffraction tomography. Part II-Cell parameter determination. Ultramicroscopy 2008, 108, 763-772. [CrossRef] [PubMed]

7. Zhang, D.; Oleynikov, P.; Hovmöller, S.; Zou, X. Collecting 3D electron diffraction data by the rotation method. Z. Für Krist. Int. J. Struct. Phys. Chem. Asp. Cryst. Mater. 2010, 225, 94-102. [CrossRef]

8. Wan, W.; Sun, J.; Su, J.; Hovmöller, S.; Zou, X. Three-dimensional rotation electron diffraction: SoftwareREDfor automated data collection and data processing. J. Appl. Crystallogr. 2013, 46, 1863-1873. [CrossRef]

9. Kolb, U.; Gorelik, T.E.; Mugnaioli, E.; Stewart, A. Structural Characterization of Organics Using Manual and Automated Electron Diffraction. Polym. Rev. 2010, 50, 385-409. [CrossRef]

10. Van Genderen, E.; Clabbers, M.T.B.; Das, P.P.; Stewart, A.; Nederlof, I.; Barentsen, K.C.; Portillo, Q.; Pannu, N.S.; Nicolopoulos, S.; Gruene, T.; et al. Ab initiostructure determination of nanocrystals of organic pharmaceutical compounds by electron diffraction at room temperature using a Timepix quantum area direct electron detector. Acta Crystallogr. Sect. A Found. Adv. 2016, 72, 236-242. [CrossRef]

11. Gruene, T.; Wennmacher, J.T.C.; Zaubitzer, C.; Holstein, J.J.; Heidler, J.; Fecteau-Lefebvre, A.; De Carlo, S.; Müller, E.; Goldie, K.N.; Regeni, I.; et al. Rapid Structure Determination of Microcrystalline Molecular Compounds Using Electron Diffraction. Angew. Chem. Int. Ed. 2018, 57, 16313-16317. [CrossRef] [PubMed]

12. Jones, C.G.; Martynowycz, M.W.; Hattne, J.; Fulton, T.J.; Stoltz, B.M.; Rodriguez, J.A.; Nelson, H.M.; Gonen, T. The CryoEM Method MicroED as a Powerful Tool for Small Molecule Structure Determination. ACS Cent. Sci. 2018, 4, 1587-1592. [CrossRef]

13. Clabbers, M.T.B.; Gruene, T.; Van Genderen, E.; Abrahams, J.P. Reducing dynamical electron scattering reveals hydrogen atoms. Acta Crystallogr. Sect. A Found. Adv. 2019, 75, 82-93. [CrossRef] [PubMed]

14. Jones, C.G.; Asay, M.; Kim, L.J.; Kleinsasser, J.F.; Saha, A.; Fulton, T.J.; Berkley, K.R.; Cascio, D.; Malyutin, A.; Conley, M.P.; et al. Characterization of Reactive Organometallic Species via MicroED. ACS Central Sci. 2019, 5, 1507-1513. [CrossRef] [PubMed]

15. Das, P.P.; Andrusenko, I.; Mugnaioli, E.; Kaduk, J.A.; Nicolopoulos, S.; Gemmi, M.; Boaz, N.C.; Gindhart, A.M.; Blanton, T. Crystal Structure of Linagliptin Hemihydrate Hemiethanolate $\left(\mathrm{C}_{25} \mathrm{H}_{28} \mathrm{~N}_{8} \mathrm{O}_{2}\right)_{2}\left(\mathrm{H}_{2} \mathrm{O}\right)\left(\mathrm{C}_{2} \mathrm{H} \mathrm{OH}\right)$ from 3D Electron Diffraction Data, Rietveld Refinement, and Density Functional Theory Optimization. Cryst. Growth Des. 2021, 21, 2019-2027. [CrossRef]

16. Halaby, S.; Martynowycz, M.W.; Zhu, Z.; Tretiak, S.; Zhugayevych, A.; Gonen, T.; Seifrid, M. Microcrystal Electron Diffraction for Molecular Design of Functional Non-Fullerene Acceptor Structures. Chem. Mater. 2021, 33, 966-977. [CrossRef]

17. Gleason, P.R.; Nannenga, B.L.; Mills, J.H. Rapid Structural Analysis of a Synthetic Non-canonical Amino Acid by Microcrystal Electron Diffraction. Front. Mol. Biosci. 2021, 7, 461. [CrossRef]

18. Palatinus, L.; Brázda, P.; Boullay, P.; Perez, O.; Klementová, M.; Petit, S.; Eigner, V.; Zaarour, M.; Mintova, S. Hydrogen positions in single nanocrystals revealed by electron diffraction. Science 2017, 355, 166-169. [CrossRef] 
19. Brázda, P.; Palatinus, L.; Babor, M. Electron diffraction determines molecular absolute configuration in a pharmaceutical nanocrystal. Science 2019, 364, 667-669. [CrossRef]

20. Shi, D.; Nannenga, B.; Iadanza, M.; Gonen, T. Three-dimensional electron crystallography of protein microcrystals. eLife 2013, 2, e01345. [CrossRef] [PubMed]

21. Nannenga, B.; Shi, D.; Leslie, A.G.W.; Gonen, T. High-resolution structure determination by continuous-rotation data collection in MicroED. Nat. Methods 2014, 11, 927-930. [CrossRef]

22. Yonekura, K.; Kato, K.; Ogasawara, M.; Tomita, M.; Toyoshima, C. Electron crystallography of ultrathin 3D protein crystals: Atomic model with charges. Proc. Natl. Acad. Sci. USA 2015, 112, 3368-3373. [CrossRef]

23. Nederlof, I.; Van Genderen, E.; Li, Y.-W.; Abrahams, J.P. A Medipix quantum area detector allows rotation electron diffraction data collection from submicrometre three-dimensional protein crystals. Acta Crystallogr. Sect. D Biol. Crystallogr. 2013, 69, 1223-1230. [CrossRef] [PubMed]

24. Clabbers, M.T.B.; Van Genderen, E.; Wan, W.; Wiegers, E.L.; Gruene, T.; Abrahams, J.P. Protein structure determination by electron diffraction using a single three-dimensional nanocrystal. Acta Crystallogr. Sect. D Struct. Biol. 2017, 73, 738-748. [CrossRef]

25. Lanza, A.; Margheritis, E.; Mugnaioli, E.; Cappello, V.; Garau, G.; Gemmi, M. Nanobeam precession-assisted 3D electron diffraction reveals a new polymorph of hen egg-white lysozyme. IUCrJ 2019, 6, 178-188. [CrossRef]

26. Gemmi, M.; Lanza, A.E. 3D electron diffraction techniques. Acta Crystallogr. Sect. B Struct. Sci. Cryst. Eng. Mater. 2019, 75, 495-504. [CrossRef] [PubMed]

27. Gallagher-Jones, M.; Bustillo, K.C.; Ophus, C.; Richards, L.S.; Ciston, J.; Lee, S.; Minor, A.M.; Rodriguez, J.A. Atomic structures determined from digitally defined nanocrystalline regions. IUCrJ 2020, 7, 490-499. [CrossRef]

28. Xu, H.; Lebrette, H.; Yang, T.; Srinivas, V.; Hovmöller, S.; Högbom, M.; Zou, X. A Rare Lysozyme Crystal Form Solved Using Highly Redundant Multiple Electron Diffraction Datasets from Micron-Sized Crystals. Structure 2018, 26, 667-675.e3. [CrossRef] [PubMed]

29. Xu, H.; Lebrette, H.; Clabbers, M.T.B.; Zhao, J.; Griese, J.J.; Zou, X.; Högbom, M. Solving a new R2lox protein structure by microcrystal electron diffraction. Sci. Adv. 2019, 5, eaax4621. [CrossRef] [PubMed]

30. Clabbers, M.T.B.; Holmes, S.; Muusse, T.W.; Vajjhala, P.R.; Thygesen, S.J.; Malde, A.K.; Hunter, D.J.B.; Croll, T.I.; Flueckiger, L.; Nanson, J.D.; et al. MyD88 TIR domain higher-order assembly interactions revealed by microcrystal electron diffraction and serial femtosecond crystallography. Nat. Commun. 2021, 12, 2578. [CrossRef]

31. Clabbers, M.T.B.; Fisher, S.Z.; Coinçon, M.; Zou, X.; Xu, H. Visualizing drug binding interactions using microcrystal electron diffraction. Commun. Biol. 2020, 3, 1-8. [CrossRef]

32. Ameerunisha, S.; Zacharias, P.S. Characterization of simple photoresponsive systems and their applications to metal ion transport. J. Chem. Soc. Perkin Trans. 2 1995, 1679-1682. [CrossRef]

33. Van Velthoven, N.; Waitschat, S.; Chavan, S.M.; Liu, P.; Smolders, S.; Vercammen, J.; Bueken, B.; Bals, S.; Lillerud, K.P.; Stock, N.; et al. Single-site metal-organic framework catalysts for the oxidative coupling of arenes via $\mathrm{C}-\mathrm{H} / \mathrm{C}-\mathrm{H}$ activation. Chem. Sci. 2019, 10, 3616-3622. [CrossRef] [PubMed]

34. Gemmi, M.; La Placa, M.G.I.; Galanis, A.S.; Rauch, E.; Nicolopoulos, S. Fast electron diffraction tomography. J. Appl. Crystallogr. 2015, 48, 718-727. [CrossRef]

35. Kabsch, W. XDS. Acta Crystallogr. Sect. D Biol. Crystallogr. 2010, 66, 125-132. [CrossRef] [PubMed]

36. Sheldrick, G.M. SHELXT-Integrated space-group and crystal-structure determination. Acta Crystallogr. Sect. A Found. Adv. 2015, 71, 3-8. [CrossRef] [PubMed]

37. Burla, M.C.; Caliandro, R.; Carrozzini, B.; Cascarano, G.L.; Cuocci, C.; Giacovazzo, C.; Mallamo, M.; Mazzone, A.; Polidori, G. Crystal structure determination and refinementviaSIR2014. J. Appl. Crystallogr. 2015, 48, 306-309. [CrossRef]

38. Sheldrick, G.M. Crystal structure refinement withSHELXL. Acta Crystallogr. Sect. C Struct. Chem. 2015, 71, 3-8. [CrossRef]

39. Hübschle, C.B.; Sheldrick, G.M.; Dittrich, B. ShelXle: A Qt graphical user interface forSHELXL. J. Appl. Crystallogr. 2011, 44, 1281-1284. [CrossRef] [PubMed]

40. Brown, G.M.; Levy, H.A. Further refinement of the structure of sucrose based on neutron-diffraction data. Acta Crystallogr. Sect. B Struct. Crystallogr. Cryst. Chem. 1973, 29, 790-797. [CrossRef] 